American Journal of Pediatrics
2020; 6(3): $172-181$
http://www.sciencepublishinggroup.com/j/ajp
doi: 10.11648 /j.ajp.20200603.12
ISSN: $2472-0887$ (Print); ISSN: $2472-0909$ (Online)

\title{
Implementation of Educative Boardgame to Improve Knowledge, Attitude and Practice of Complementary Feeding in Stunting Locus at Central Lombok
}

\author{
Titi Pambudi Karuniawaty ${ }^{1,}$, , Linda Silvana Sari ${ }^{1}$, Adnanto Wiweko ${ }^{2}$, Intan Karmila ${ }^{2}$ \\ ${ }^{1}$ Department of Child Health, Faculty of Medicine, Mataram University, Mataram, Indonesia \\ ${ }^{2}$ Faculty of Medicine, Mataram University, Mataram, Indonesia
}

Email address:

tp_karuniawaty@yahoo.com (T. P. Karuniawaty), lindasilvanasari@gmail.com (L. S. Sari), a_wiweko@yahoo.com (A. Wiweko), ikarmila11@gmail.com (I. Karmila)

*Corresponding author

\section{To cite this article:}

Titi Pambudi Karuniawaty, Linda Silvana Sari, Adnanto Wiweko, Intan Karmila. Implementation of Educative Boardgame to Improve Knowledge, Attitude and Practice of Complementary Feeding in Stunting Locus at Central Lombok. American Journal of Pediatrics. Vol. 6, No. 3, 2020, pp. 172-181. doi: 10.11648/j.ajp.20200603.12

Received: March 7, 2020; Accepted: April 8, 2020; Published: May 12, 2020

\begin{abstract}
Complementary feeding practice (CFP) contributes to high incidence of stunting in West Nusa Tenggara especially in Central Lombok. The complementary feeding program for infants and children was launched by government as a strategy to combat stunting in order to realize the Generasi Emas NTB 2025. For this reason, the provision of complementary feeding has been introduced into maternal and child health book $(\mathrm{MCH})$, but has not met all WHO recommendations. This interventional, quasi experimental, pre-post test design study, aimed to develop board game as an educational media about stunting and CFP and to assess its effectiveness to increase parents' knowledge, attitude and practice (KAP) regarding CFP in Central Lombok as stunting locus. This study located at Sukadana village that was selected randomly. Subjects were parents of children aged 6-12 months old whom met inclusion and exclusion criteria. KAP assessment was conducted by using validated questionnaire, which was carried out before and after GiMPASI intervention, educational game. From 42 subjects involved in this study we found significant differences both in knowledge scores about complementary food (CF) feeding pre and post intervention ( $3.43 \pm 1.70$ vs $4.83 \pm 1.64 ; \mathrm{p}=0.001)$ and in attitude scores ( $10.55 \pm 2.77$ vs. $12.33 \pm 2.67 ; \mathrm{p}=0.002)$. Likewise, there

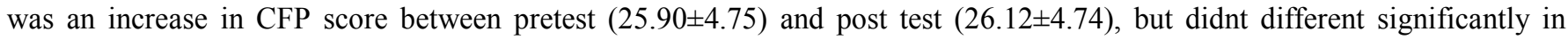
paired t-test analysis ( $\mathrm{p}=0.79$ ). GiMPASI can be used as an effective educational media to increase parents' knowledge and attitude regarding stunting and CFP. GiMPASI can be developed as part of infant and child complementary feeding against stunting.
\end{abstract}

Keywords: Stunting, Complementary Feeding, Food, Board Game, Educational Media

\section{Introduction}

In early childhood, linear growth has been considered as marker of healthy growth because of its association with development of cognitive, language, sensory and motor capacity $[1,2]$. Stunting reflects chronic malnutrition problem that has occurred since antenatal, intrauterine and postnatal period and is considered as the best indicator that reflects the well-being and social condition of a child $[3,6,7$, $11]$.

Malnutrition in children, includes stunting, is a series effects of various factors from multi-sectoral response [15]. Factors that contribute to stunting including family and household factors (maternal and home environment factors), inadequate complementary feeding (CF), breast milk (BM) and infection. Maternal factors affect child both in period of pregnancy and the period before pregnancy, this can affect the growth and development of intergeneration [12]. Stunting women are prone to experience intrauterine growth retardation (IUGR) [8]. Sasak, a native tribe in West Nusa 
Tenggara, has several eating habits, including preference of spicy food rather than animal protein, rarely consume vegetables, inappropiate complementary food, taboo eating habits for pregnant women of certain foods such as squid and fish, permissive parenting style and patrilineal system thus

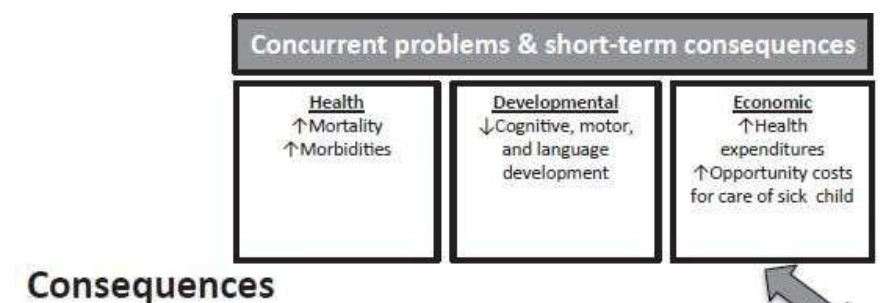

\section{Consequences}

\section{Stunted Growth and Development}

allowed children to eat their favourite food which are not nutritious [8].

WHO has released a conceptual framework of stunting in childhood as follows:

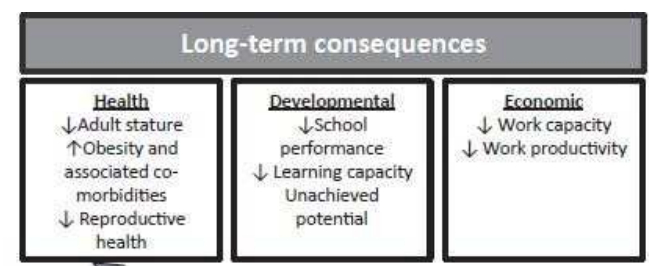

\section{Causes}

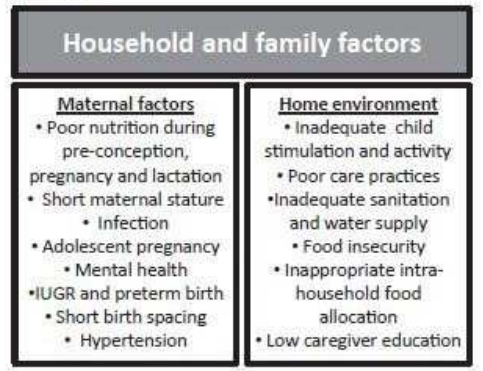

\section{Context}

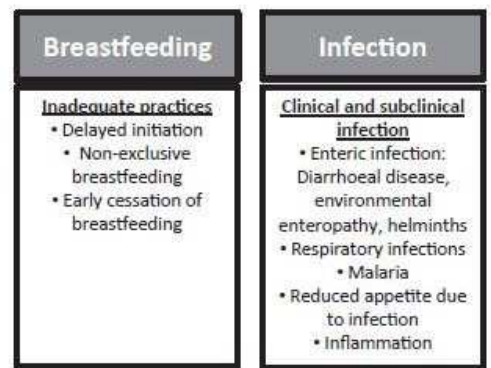

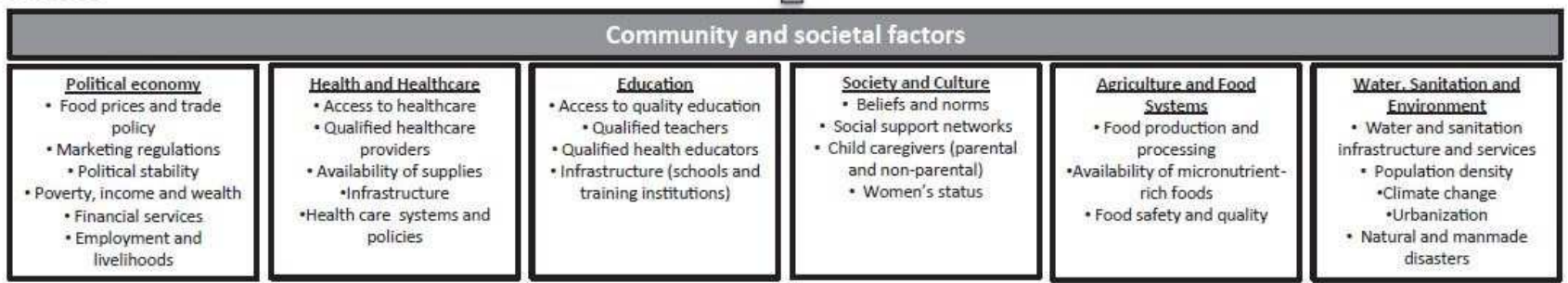

Figure 1. WHO conceptual framework Childhood Stunting: Context, Causes, and Consequences, with an emphasis on complementary feeding."

The provincial government of NTB has initiated the Generasi Emas NTB (GEN) program which aimed to produce superior generation by 2025 . The GEN Program is an integrated program in various sectors with focus on growth and development in children. The program includes monitoring of pregnant women by GEN and village facilitators as well as providing child health services including neonatal, infant, toddler and child health services. Growth monitoring has been implemented in child health services program with $84.57 \%$ toddler under five years old in 2015. The Health department also collaborated with NTB Health Institute to carry out the Action of Care in the form of A Thousand Day Action (Aksi Seribu Hari/ASHAR) [5].

The term play can be interpreted as activity that purely seeks pleasure without lose. While the second understanding, playing (games) is an activity carried out in order to seek pleasure and satisfaction but is characterized by win-lose.
Game play roles in the development of children's cognitive, social and emotional function.

Board game is a game that uses board which can be placed by several of pawns on it, with certain rules that limit the position and movement of the pawn based on the appearance of the dice as a reference. This game ends at certain point where movement can no longer be done. Movement or placement of a pawn affects the situation of the board and other pawns.

Board games has been known for a long time for cognitive purposes in various fields such as socio-culture, archeology, mathematics, philosophy, health and recently developed interdisciplinary. There are many types of board games in cognitive research, including war games, characterized by destroying opponents (eg. chess); race games, characterized by the target that must be achieved to defeat opponent (eg. backgammon); and alignment games, that emphasize strategies for winning games (eg.tic-tac-toe). 
One of the most famous board game is ladder snake game that originated in India in 1870 . It can be done by two or more person, using a checkered striped board with several pictures of snakes and stairs connecting the boxes. This type of game is the most developed because of its simplicity and well known. The gameplay is clear and certain material or content can be included easily in the snakes and ladders game so as to be able to provide greater benefits than just for fun purposes.

At present, the shape and appearance of snakes and ladders game varies greatly from the small size of carriable board to the size of a room so that it can be played in large groups combined with physical activity and also as computer game which can be played individually.

This research is part of the umbrella research of stunting in Central Lombok stunting locus, supervised by Maternal and Child Health research group. This study focus on the effectiveness of educational board games to increase knowledge, attitudes and practices of giving complementary food to stunting children and their parents.

\section{Materials and Method}

This was an interventional, quasi experimental, pre-post test design study, which applied educational game interventions to increase knowledge, attitude and practice of complementary food and stunting before and after educative game intervention was carried out. This research was conducted at the stunting locus in Central Lombok Regency, NTB from June 2019.

The study population consisted of parents with stunting children in Central Lombok, West Nusa Tenggara and conducted in a village, chosed randomly from 10 stunting village locus.

Subjects were chose randomly and agreed to participate by signing informed consent.

\subsection{Variabel Definition}

Stunting: nutritional status based on a comparison between length or height according to toddler age against the standard of WHO-MGRS (Multicentre Growth Reference Study) 2005 which z-score below -2SD (short/stunted) or z-score that is below -3SD (very short/severely stunted).

Knowledge: collection of facts, information and ideas possessed by someone, in this study refers to parents' understanding of stunting.

Attitude: way of thinking or feeling about someone or something and cannot always be observed directly.

Behavior: attitude or habit that can be observed, usually done without conscious decisions and in response to something that happens in the environment.

Gender: categorized into male and female.

Age: calculated from the difference between date of birth and date of sampling. Subsequently categorized into young adults (19-45 years old), adults (46-64 years old), and advanced adults ( $\geq 65$ years old).

Education: duration of formal education that subject posses, divided into three categories: low (below 9 years eg. elementary, junior high school), moderate (senior high school), high (eg. university degree).

Socio-economy status: based on the family income devided into 3 categories based on local minimum wage, which are low-middle class (less than Rp. 1,850,000), middle class (Rp. 1,850,000.-3,700,000), middle-high class (more than Rp. 3,700,000).

Educational game: a playing tool that has educational value, in the form of board game that contains information about complementary food and stunting.

Knowledge about complementary feeding and stunting: things parents need to know about definition, causes, symptoms and ways to prevent stunting. Knowledge level is expressed as good and bad based on the proportion of correct answers in the questionnaire. Knowledge is stated as good if it is above the average proportion of correct answers from all research subjects, while bad if it is below the average proportion of correct answers from all research subjects.

Inclusion criteria were:

1. Parents live and registered in stunting village, Central Lombok, West Nusa Tenggara whom can be represented by mother or guardian of stunting children.

2. Parents of stunting children aged 6-12 months old.

3. Parents who agree to participate by signing an informed consent

Exclusion criteria were: parents of uncoperative children, parents who didn't complete questionnaire.

The sample size calculation is based on formula for numerical comparative analysis of multiple pairs twice measurements with minimum sample size 38 subjects.

\subsection{Game Method}

The educational game GiMPASI is a playing tool in the form of cards (card games) in groups, contain educational value about stunting and practice of complementary feeding, to improve players' knowledge, attitudes and behavior regarding stunting and practice of giving complementary feeding. This game is played by 3-6 players which can be aimed to parents, posyandu facilitators and health workers.

This game must be accompanied by facilitator with duration of $>30$ minutes. The components of GiMPASI, including:

(1) 50 material cards

On the material card there are questions with right / wrong answers about stunting (10 questions) and complementary feeding (40 questions) that must be answered by player. Material cards consist of beans and processed, meat and eggs, vegetables, rice and tubers. Each material is symbolized by picture on front page of the card

(2) 19 menu cards

On the menu card there is a menu title that must be cooked by player with the instructions of material card symbol and tool symbol at the top of the menu card. List of 19 GiMPASI menus including: boiled fish filter, spinach rice porridge, 
potato spinach porridge, tuna soybean porridge, red rice tempeh porridge, soybean chicken porridge, baby bean potato porridge, tempeh rice filter team, red bean chicken liver team, green bean team rice, spinach tofu rice team, sweet potato chicken liver team, chopped chicken cauliflower team, chicken claw soup, vegetable tofu chicken, tofu stir-fried rice, rice balls, yellow tempeh, tofu stir-fried meat

(3) 30 tool cards

Contain cooking utensils such as knive, pan and filter. The knife functions when processing chopped food for children
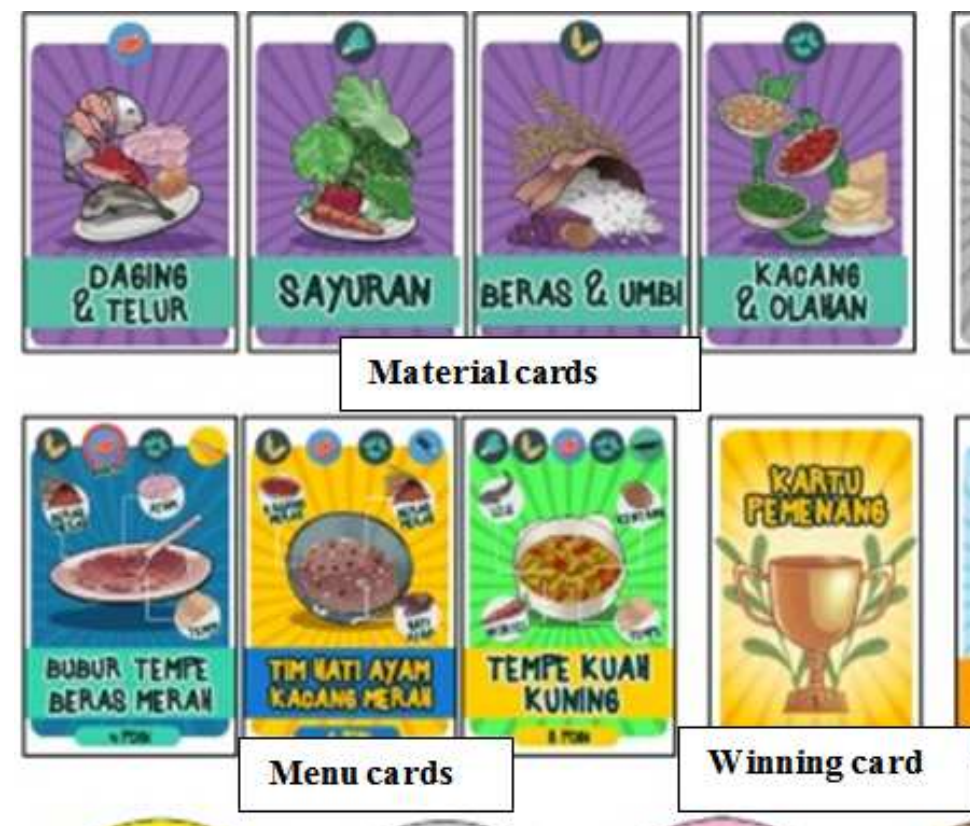

aged 9-12 months. Frying pan is a cooking tool to process family food for children $>1$ year old. The filter tool for children aged 6 months (fine filter) and ages 8-9 months (coarse strain).

(4) 25 opportunity cards

Contains instructions and clues that can be used immediately after taking the opportunity card on the deck and / or can be used to substitute for material cards and tool cards.
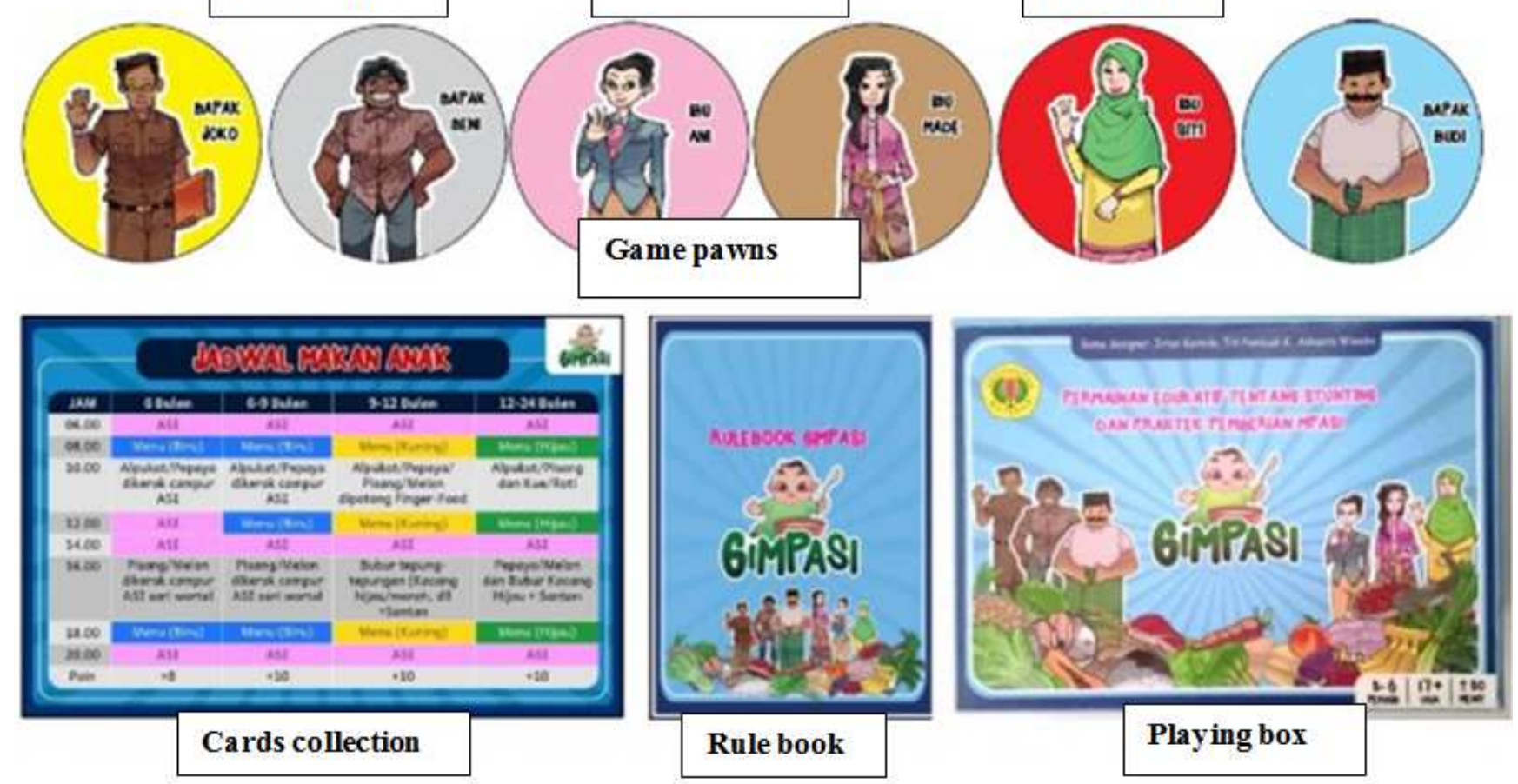

Figure 2. Components of GiMPASI: Cards collection, rule book, playing box, game pawns, tool cards, winning card, menu cards, chance cards, material cards. 


\subsection{Game Preparation}

1) Shuffle all menu cards, then draw cards according to the number of players to get the menu deck: 3 players $=12$ cards, 4 players $=16$ cards, 5-6 players $=19$ cards.

2) Shuffle the chance card, then cover it in playing area.

3) Shuffle the ingredients cards, then arrange 25 cards of materials randomly to form a $5 \times 5$ square card, with the side of the card that has a picture of the food material facing up.

4) The remaining material cards are stored on the material card decks.

5) Hand out each player 3 menu cards.

6) Pay attention to the menu card. On some menu cards there are free ingredients that can be directly taken free of charge at the beginning of the game.

7) Each player chooses one player's pawn, then places a pawn in the middle of a deck of material cards.

8) Each character gets a tool card bonus eg:

$\begin{array}{ll}\text { Mr Joko } & \text { Bonus filter } \\ \text { Mr Beni } & \text { Bonus filter } \\ \text { Mrs Ani } & \text { Bonus frying pan } \\ \text { Mrs Made } & \text { Bonus frying pan } \\ \text { Mrs Siti } & \text { Bonus knife } \\ \text { Mr Budi } & \text { Bonus knife }\end{array}$

\subsection{Game Plot}

1) First player is determined randomly, then take turns randomly.

2) In each turn, player can maximally moves two card slots (may be 1 or 2 plots) up / down / left / right / diagonal.

3) Take the last card the player holds.

4) Answer questions behind those card. If the answer is correct, then the player can save thus answered material card. If wrong, return the material card goes to the lowest material card deck

5) On some material cards, there is a bonus. Bonus can only be earned if the player answers correctly.

6) Action on the opportunity card, bonus card can only be done during the player's turn.

\subsection{End of Game}

The game ends if all menu cards have been cooked (claimed by the player). Points calculation for each player based on following conditions:

1. Each menu card is worthed as the stated points on the card.

2. Each unused material card is valued 5 points.

3. Each symptom card will deduct 5 points.

Player who gets the highest points wins. If it is a draw, then the player who cooks most menu wins the game.

Quantitative data obtained from measurements are processed and displayed descriptively in graphs and tables, then statistically analyzed to compare the average score of knowledge and perception before and after intervention by using paired t-test if the data is normally distributed or Wilcoxon test as an alternative. The results of the data analysis were strengthened qualitatively.

\section{Results}

Total 42 subjects from Sukadana village, Central Lombok participated in this study. Most of them were 17-25 years old, $41 \%$, with an average age of 27.86 years old. More than $60 \%$ of the subjects are categorized as low level of education, which is under 9 years.

\section{Distribution of mother's age}

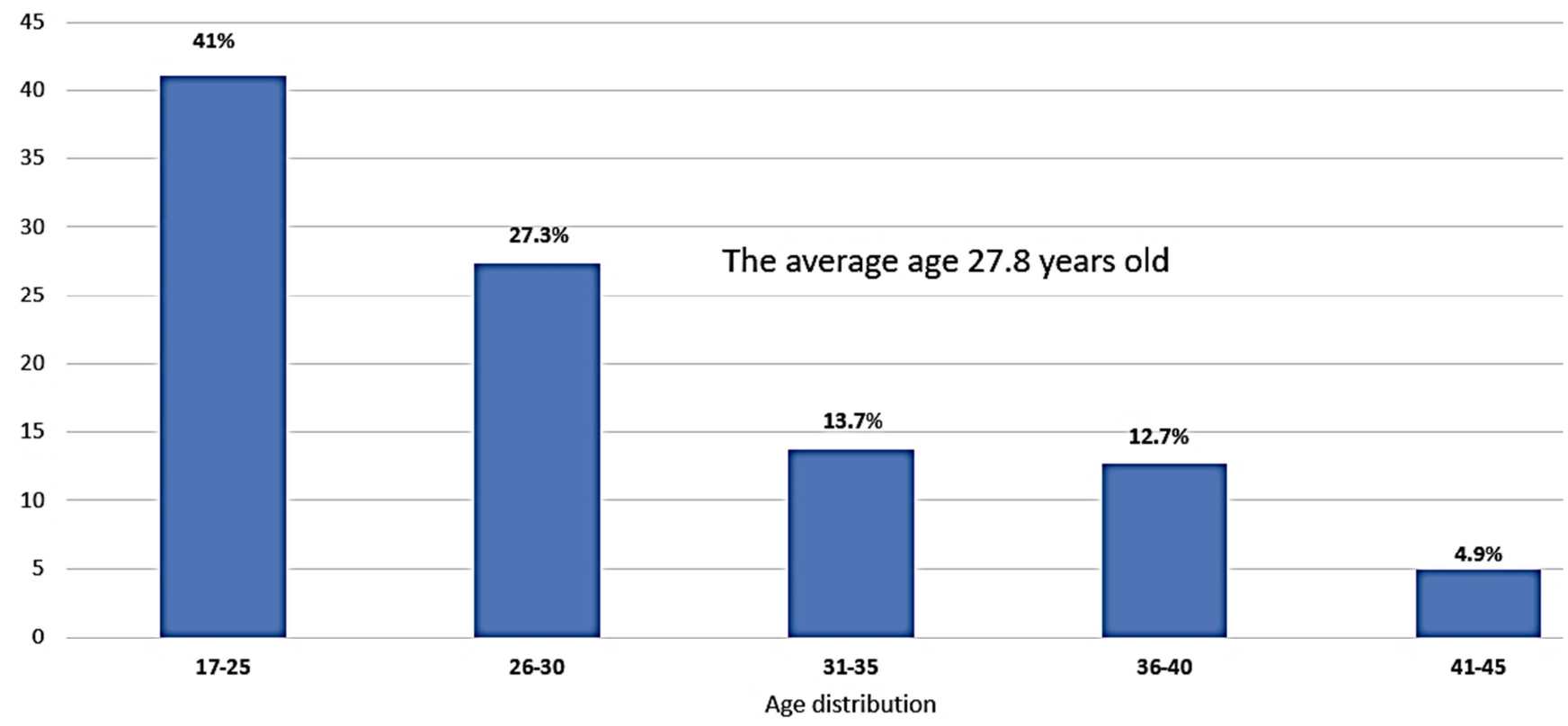

Figure 3. Age distribution. 


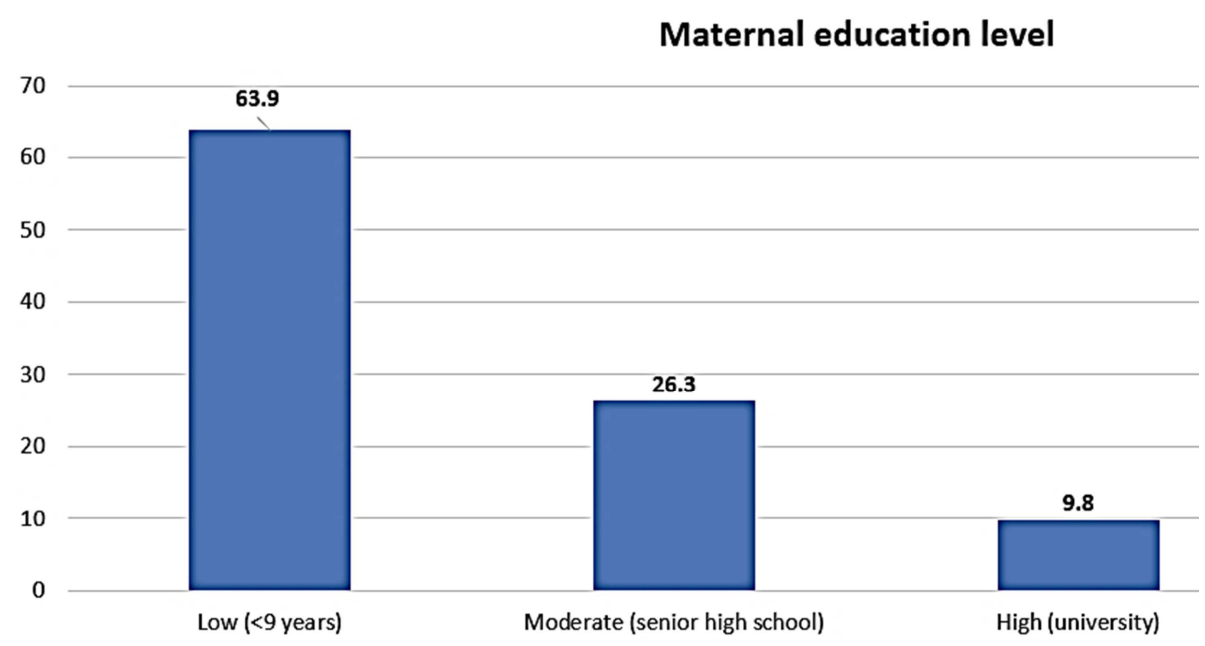

Figure 4. Level of education distribution.

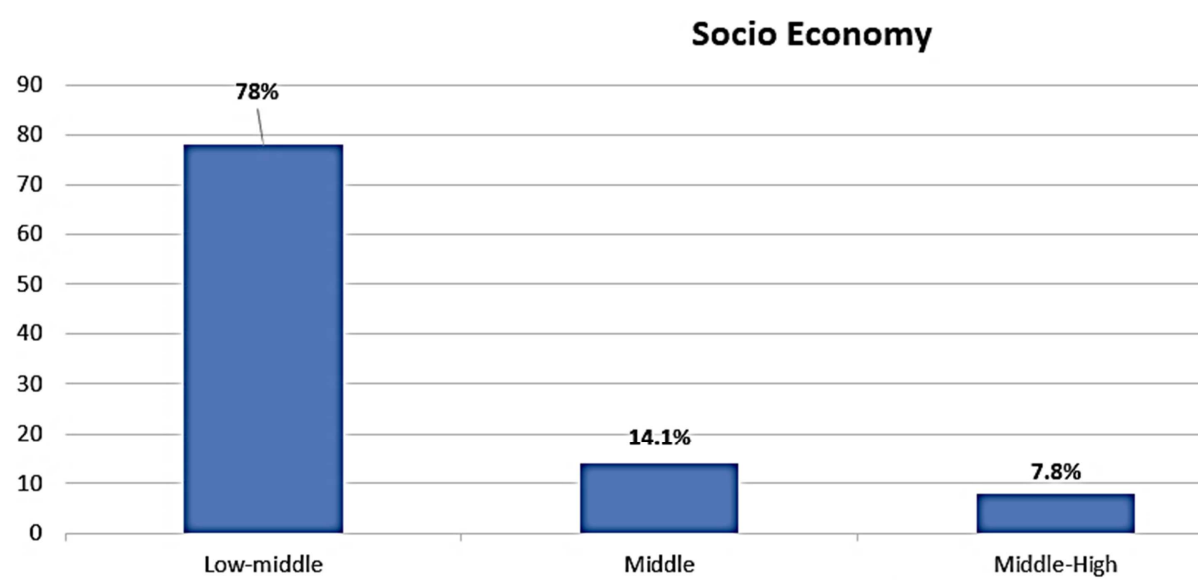

Figure 5. Socio-Economy distribution

More than two-thirds of participants $(78.0 \%)$ had income below the local minimum wage, which was less than Rp. $1,850,000$.

Table 1. Respondents knowledge of complementary feeding.

\begin{tabular}{lll}
\hline Knowledge Aspects (Correct answer) & Pre Test $\mathbf{n}(\mathbf{\%})$ & Post Test n (\%) \\
\hline Age of introduction CF & $22(32.8)$ & $25(37.3)$ \\
The adequacy of macronutrients & $15(22.4)$ & $16(23.9)$ \\
Choices of CF & $1(1.5)$ & $7(10.4)$ \\
Food safety & $37(55.2)$ & $40(59.7)$ \\
Introduction of additional components in CF & $22(32.8)$ & $37(55.2)$ \\
Duration of feeding & $21(31.3)$ & $39(58.2)$ \\
Administration of Milk formula & $19(28.4)$ & $39(58.2)$ \\
Sources of protein CF & $12(17.9)$ & $36(53.7)$ \\
The amount of vegetables in CF component & $18(26.9)$ & $38(56.7)$ \\
\hline
\end{tabular}

Aspects that had higher score before the intervention were food safety and age of introduction of complementary feeding, while knowledge aspects regarding the selection of complementary food as well as protein sources in complementary feeding were lower (Table 1).

There were 6 questions regarding aspects of attitude that were asked to the subjects (Table 2). The aspects that get high score include the age of introduction of complementary feeding at 6 months and continuing breastfeeding (BF) until the child is 2 years old, while the low score aspect is regarding nutritional content and food diversity.
Table 2. Attitudes of respondents complementary feeding.

\begin{tabular}{lll}
\hline Attitude Aspects (Correct answer) & $\begin{array}{l}\text { Pre Test } \\
\text { n (\%) }\end{array}$ & $\begin{array}{l}\text { Post Test } \\
\text { n (\%) }\end{array}$ \\
\hline Age of introduction of CF & $43(64.2)$ & $54(80.6)$ \\
Continue BF up to 2 years old & $30(44.8)$ & $39(58.2)$ \\
Responsive feeding & $17(25.4)$ & $22(32.8)$ \\
Feeding duration & $20(29.9)$ & $20(29.9)$ \\
Nutrient content & $5(7.5)$ & $17(25.4)$ \\
Food diversity & $14(20.9)$ & $20(29.9)$ \\
\hline
\end{tabular}

There were 76 questions regarding behavioral aspects that 
were asked to subjects (Table 3). Aspect that got high score were the behavior of continuing breastfeeding until the child is 2 years old and feeding behavior according to the correct frequency, while the lowest behavioral aspect concerns the duration of feeding and the adequacy of macronutrients in complementary food.

Table 3. Respondents' complementary feeding patern.

\begin{tabular}{lll}
\hline Behavioral Aspects (Correct answer) & $\begin{array}{l}\text { Pre Test } \\
\text { n (\%) }\end{array}$ & $\begin{array}{l}\text { Post Test } \\
\text { n (\%) }\end{array}$ \\
\hline Frequency of feeding & $37(55.2)$ & $23(34.3)$ \\
Continue breastfeeding & $53(79.1)$ & $43(64.2)$ \\
Responsive feeding practice & $20(29.9)$ & $25(37.3)$ \\
Hygienic behavior & $34(50.7)$ & $35(52.2)$ \\
Food safety behavior & $34(50.7)$ & $39(58.2)$ \\
Duration of feeding & $7(10.4)$ & $11(16.4)$ \\
The adequacy of macronutrients & $8(11.9)$ & $4(6)$ \\
\hline
\end{tabular}

T-paired analysis showed that there were significant differences in knowledge scores regarding stunting and $\mathrm{CF}$ administration before and after the intervention $(3.43 \pm 1.70 \mathrm{vs}$ $4.83 \pm 1.64 ; \mathrm{p}=0.001)$ and attitude scores $(10.55 \pm 2.77$ vs $12.33 \pm 2.67 ; \mathrm{p}=0.002)$. Likewise, there was an increase in the mean behavior score regarding stunting and $\mathrm{CF}$ administration before $(25.90 \pm 4.75)$ and after intervention (26.12 \pm 4.74$)$, but there was no significant differences in the paired t-test analysis $(\mathrm{p}=0.79)$.

\section{Discussion}

Complementary feeding (CF) is applied when breastmilk alone is not enough to fullfill the nutritional needs of children, so other food is needed in line with breastfeeding [13]. Knowledge, attitudes and behavior of parents towards $\mathrm{CF}$ are important in the success of $\mathrm{CF}$ practice. WHO recommended the introduction of $\mathrm{CF}$ at 6 months old. Parents' knowledge of CF introduction varied from various studies. In this study, parental knowledge of the introduction of suitable CF was $32.8 \%$. This was lower compared to several studies, such as Pakistan (54\%), Karachi (57.2\%) and Ghana (60\%) [14]. Other studies in Southern Ethiopia, 72.5\% mothers with children aged 6-23 months old knew the right time to introduce $\mathrm{CF}$, but lower than the results of other study in South India in 2017 (77.5\%) [14, 15] Aggarwal et al. found only $17.5 \%$ mothers started $\mathrm{CF}$ at the recommended time and research in the village of Delhi showed only $16.6 \%$ parents initiated the administration of $\mathrm{CF}$ at the right time. The study showed the level of parental knowledge about introduction time of $\mathrm{CF}$ was lower than this study. After the intervention, this study found an increase in parental knowledge about the introduction time of CF. In contrast, parental attitudes toward initiation of CF showed good results with $64.2 \%$ in control group.

WHO recommended the frequency of CF 2 to 3 times in children aged 6-8 months old and 3 to 4 times in children aged 9-12 months old, with 1 to 2 intervals each day. Research in Nigeria showed only half of their subjects knew the correct frequency of CF, but other studies in Ghana showed almost all respondents knew the recommended CF frequency. Another similar study in Allahabad showed only $38.7 \%$ children received appropriate CF [15]. This study found that $55.2 \%$ parents gave $\mathrm{CF}$ with the right frequency. This finding is similar to previous studies in Bahir Dar, Ethiopia (47\%), India (48.6\%) and Pakistan (62\%) [16-18].

In addition to the minimal frequency of $\mathrm{CF}$, the adequacy of the macronutrients and micronutrients is also crucial. $\mathrm{CF}$ must vary with sufficient macronutrients and micronutrients. The need for micronutrients in the first 2 years of life is associated with the speed of growth and development of children. After the intervention, the parents' attitude toward the adequacy of macronutrients increased to $25.4 \%$. Another study in 2018 showed that $27.3 \%$ of mothers aware that adding oil into porridge could increase the nutritional content of the porridge and $31.8 \%$ mothers knew that CF had to be balanced [20]. Other studies in Sri Lanka showed that oil was introduced to $84.9 \%$ children at 12 months of age [21]. In our study, only $34.3 \%$ parents knew the fat component in $\mathrm{CF}$ before the intervention. Knowledge of the fat component of $\mathrm{CF}$ increased after the intervention into $55.2 \%$.

Research conducted in Urganda reported that majority children were given cereal in the last 24 hours and only $0.5 \%$ mothers gave meat and milk-derived products. Cereal-based foods alone are not sufficient to meet nutritional adequacy [22]. WHO recommended that mothers feed their child with local food that contain calories, protein, minerals and vitamins. Our research showed low level of parental knowledge about protein sources before the intervention, but then increases after the intervention.

Fortified CF can meet nutritional intake needs [13] Hasnain et al reported that $82 \%$ of their study subjects knew that home made $\mathrm{CF}$ was good, but only $42 \%$ gave home made CF to their children [18]. Our research showed only $10.4 \%$ respondents know that fortified foods can be used as CF.

Food diversity is known to be the key to good food quality. WHO guidelines recommended that children should eat meat, fish or eggs as often as possible. Vegetables and fruits that are rich in vitamin A also need to be consumed every day. In our study, parental attitudes toward CF diversity was still low $(20.9 \%)$ before the intervention. This percentage increased after the intervention but still at low level (29.9\%). Other research showed majority of children consumed wheat, tubers, rice, bread and cassava. Consumption of foods rich in iron was relatively low, because animal protein is not affordable due to financial problems. Based on research in Sri Lanka, animal protein intake was very low, fish and eggs were only consumed by $25 \%$ and $18 \%$ children. However, another study in Galle Sri Lanka, showed the introduction of fish and eggs to children was high, which amounted to $75 \%$ of fish consumption and $63 \%$ of egg consumption. Consumption of foods rich in vitamin A such as pumpkin and carrots was also high (97\% and 90\%) [21]. Senarath et al in his study found that eating variations in children increased 
with age (40.1\% in children aged 6-8 months old and $82.5 \%$ in children aged 18-23 months old) [23].

The preparation of making and storing complementary food also play important role in the practice of CF. Parents and children are recommended to wash their hands before eating. In our study, the behavior of parents washing hands with soap and water was moderate before the intervention $(50.7 \%)$. Hand washing practice was found increase after the intervention. Mihreite also found similar results, the majority of mothers in the study had high knowledge of the practice of hand washing [24]. Such knowledge includes: washing hands before preparing $\mathrm{CF}(44.5 \%)$ and using treated water (46.4\%). Madhu et al reported 200 participants in their study, $96 \%$ cleaned their hands and cooking utensils before giving food, $60 \%$ washed children's hands before eating and $61 \%$ boiled water to drink [22].

Complementary food needs to be given responsively (responsive feeding) as recommended by WHO. Responsive feeding includes being sensitive to signs of hunger and satiety of children, feeding slowly and patiently, combining the texture and taste of various foods, minimizing distractions during meal times and inviting children to communicate during meals. Inappropriate eating behavior plays role in the occurrence of stunting. Parents are still not awar the importance of responsive feeding [25]. Only 45.5\% mothers reported the importance of responsive feeding to ensure optimal intake of children [20]. In this study, parents' knowledge of the recommended duration of eating is low. This finding was followed by low rate of responsive feeding behavior $(29.2 \%)$ before the intervention.

Continuing breastfeeding until the age of 2 years old or more contributes to maximizing children's growth, due to the content of essential fatty acids and energy in BM. BM also has important micronutrient content [25]. In this study, the attitude of parents to continue breastfeeding before the intervention was $44.8 \%$. The attitude of parents towards breastfeeding increased after the intervention to $58.2 \%$. This finding is lower compared to other studies in Ethiopia, about $92 \%$ and $94 \%$ of mothers continued breastfeeding their children until the age of 1 year old and 2 years old [16]. The majority of mothers who participated in the study were housewives thereby increasing the chances of staying giving BM to children [15]. Meanwhile, our study showed $79.1 \%$ of mothers continued breastfeeding.

Education is an important determinant of children's growth and development. There is a relationship between the level of parental education with the practice of proper feeding. Maternal education was found has significant role in child feeding in studies in five countries in Asia [23]. However, Seram et al reported no significant relationship between parental education and parental knowledge about CF [26]. These results was similar to other studies in rural areas in Bangladesh. The study found that maternal education was not related to the time of introduction of $\mathrm{CF}$. Maternal knowledge or education may not be the main determinant of $\mathrm{CF}$ behavior [20]. Seranath et al in his study showed linear correlation between feeding frequency and maternal education, but no association was found with other $\mathrm{CF}$ indicators such as the time of $\mathrm{CF}$ introduction, food diversity and minimum food intake recommended. Compared to mothers with higher level of education, those who do not go to school or only graduate from secondary school were risky of having low diversity of eating (OR 1.97 and1.48) [23]. The results of this study was in line with studies in Kenya which found mother's level of education and knowledge were positively correlated with prohibited food [27].

Economic status plays role in meeting household needs including CF. Poverty is one of the behavioral factors in giving inappropriate complementary food. The study at Wollow found that households with higher incomes had better CF behavior related to its diversity [28]. Several other studies also showed that low income was a major factor inhibiting the provision of CF. Low income contributes to the inability to reach minimum food frequencies and food diversity [28, 29].

The study showed that diets in infants and children in countries with low incomes had iron, zinc, and vitamin B6 deficiency [25]. These findings were confirmed by other studies in Sri Lanka, which showed that the diversity of food gradually decreased with lower income [23].

Research in Wanogo, Southern Ethiopia in 2017 showed that culture plays major role in children's eating behavior. The eating habit in community was not in accordance with the guidelines for child feeding that has been recommended and responsible for increasing CF deviant behavior by $2.4 \%$. Most subjects stated that parents, especially husbands, were prioritize while the remaining would be given to children [28]. Other studies in China found that mothers introduce CF to children before 6 months, most often at 3 months old. They believe that introducing traditional Chinese CF earlier can be beneficial for children, such as strengthening bone growth, making children full longer, chew learning for children, accelerating growth and improve the digestive system [27]. Similar to the study in Lubao, Kenya reported that most parents gave their children porridge at 1 month old because porridge could make their child strong. The results of this study indicated that culture was the reason 54\% parents forbid children from eating some food. Restrictions on certain foods and taboos affect children's eating patterns. The most common taboo in that area is not giving egg to children because egg was believed to cause speech delay. Some parts of the meat also shouldn't be eaten by child or mother because it was served for father and some local residents believe that grilled fish with little ash could induce snooring in children who consumed it.

Although it has the same general objectives as other studies, this study aimed to show different parameters on the effectiveness of educational interventions in the GiMPASI game by measuring changes in parents' knowledge, attitudes and behavior at interval of four weeks. It can be observed that the educational game GiMPASI had positive impact on parents' knowledge and attitudes. Research by Shi et al in China which collected second data at 6-month intervals successfully showed that the intervention group had better 
CF behavior. However, in this study the intervention was slightly different from ours which home visits were carried out as an additional approach combined with group training and the distribution of manuals.

The participation of local health workers with health and regional facilitators are important to ensure the success of this intervention in community. This research collaborates with health workers in the village. However, several things need to be improved such as the provision of interpersonal sessions with research subjects in the form of individual counseling and home visits. This method was implemented by Hotz and Gibson in 2005 in Malawi which resulted to an increase in parental knowledge and habits regarding food preparation. Another study by Shi et al in 2009 also showed that the involvement of family members, especially husband and mother-in-law is also important to create a supportive environment for increasing parents in $\mathrm{CF}$.

This research is vulnerable to selection bias conducted by the research team because it did not do blinding. We try to minimize bias by training all research teams prior to the intervention to provide similar and standardized interventions in both intervention groups. We also cannot conduct individual consultations and home visits, which play role in consolidating the knowledge of research subjects on the new information provided. In addition, we only included one parent for each child so that other family members who might have an influence on parents such as husband and mother-in-law were not included in the subject of research and intervention. We also note that follow-up at longer intervals such as three and six months should be included in the research design to find out longer changes in the knowledge, attitudes, and behavior of older people towards CF.

\section{Conclusion}

The educational game GiMPASI can be used as an effective educational media to increase the knowledge and attitudes of parents regarding the stunting and practice of CF. GiMPASI can be developed as part of infant and child supplement feeding training in the context of stunting prevention and treatment. Improving parents' knowledge, attitudes and behavior towards CF requires sectoral approaches. Further research is needed to see the long-term effectiveness of the intervention.

\section{Funding}

This research was funded by DIPA BLU (PNBP) Mataram University.

\section{References}

[1] Kementerian Kesehatan RI. Situasi dan Analisis Gizi. Jakarta: Infodatin; 2015.

[2] de Onis M, Blössner M, Borghi E. Prevalence and trends of stunting among pre-school children, 1990-2020. Public Health Nutr. 2012; 15 (01): 142-8.

[3] Dinas Kesehatan Provinsi Nusa Tenggara Barat. Profil Kesehatan Provinsi Nusa Tenggara Barat 2015. Pemerintah Provinsi NTB; 2016.

[4] Millennium Challenge Account Indonesia. Stunting dan Masa Depan Indonesia. Jakarta: MCA Indonesia. 2015.

[5] Kementerian Kesehatan RI. Rencana Strategis Kementerian Kesehatan Tahun 2015-2019, Keputusan Menteri Kesehatan RI nomor HK. 02. 02/Menkes/52/2015. Jakarta: Kementerian Kesehatan RI; 2015.

[6] Pérez Lizaur AB. Complementary Feeding: Report of the Global Consultation, Summary of Guiding Principles. Gac Médica México. 2011; 147 Suppl (December): 39-45.

[7] Blaney S, Februhartanty J, Sukotjo S. Feeding perilakus among Indonesian children above six months of age: A literature review on their magnitude and quality (part 1). Asia Pac J Clin Nutr. 2015; 24 (1): 16-27.

[8] Abeshu MA, Lelisa A, Geleta B. Complementary Feeding: Review of Recommendations, Feeding Practices, and Adequacy of Homemade Complementary Food Preparations in Developing Countries - Lessons from Ethiopia. Front Nutr. 2016; 3 (October).

[9] Nurbaiti L, Adi AC, Devi SR, Harthana T. Kebiasaan makan balita stunting pada masyarakat Suku Sasak: Tinjauan 1000 hari pertama kehidupan (HPK). Masy Kebud Dan Polit. 2014 Apr1; 27 (2): 104-12.

[10] Blaney S, Februhartanty J, Sukotjo S. Feeding practices among Indonesian children above six months of age: A literature review on their potential determinants (part 2). Asia Pac J Clin Nutr. 2015; 24 (1): 28-37.

[11] Fahmida U, Kolopaking R, Santika O, Sriani S, Umar J, Htet MK, et al. Effectiveness in improving knowledge, practices, and intakes of "key problem nutrients" of a complementary feeding intervention developed by using linear programming: experience in Lombok, Indonesia. Am J Clin Nutr. 2015; 101 (3): 455-61.

[12] Olatona FA, Adenihun JO. Complementary Feeding Knowledge, Practice, and Dietary Diversity among Mothers of Under-Five Children in an Urban Community in Lagos State, Nigeria. 2017; 6 (1): 46-59.

[13] Rao S, Pm S, Unnikrishnan B, Hegde A, College KM. Study of complementary feeding practices among mothers of children aged six months to two years - A study from coastal south India. 2011; 252-7.

[14] Demilew YM, Tafere TE, Abitew DB. Infant and young child feeding practice among mothers with $0-24$ months old children in Slum areas of Bahir Dar City. 2017; 1-9.

[15] Communication S. Short Communication A Study on Infant and Young Child Feeding Practice among Mothers Attending an Urban Health Center in East Delhi. 2012; 56 (4): 19-22.

[16] Hasnain S, Majrooh MA, Anjum R. Knowledge and practice of mothers for complementary feeding in babies visiting pediatrics outpatient department of Jinnah hospital, Lahore. Biomedica 2013, 29 (4): 221-230. 
[17] Dewey KG, Adu-Afarwuah S. Review Article Systematic review of the efficacy and effectiveness of complementary feeding interventions in developing countries. 2008; 24-85.

[18] Owais A, Suchdev PS, Schwartz B, Kleinbaum DG, Faruque ASG, Das SK, et al. Maternal knowledge and attitudes towards complementary feeding in relation to timing of its initiation in rural Bangladesh. BMC Nutrition 5 (7). 2019; 18.

[19] Bandara T, Hettiarachchi M, Liyanage C, Amarasena S. Current infant feeding practice and impact on growth in babies during the second half of infancy. J Hum Nutr Diet. 2015 Aug; 28 (4): 366-74.

[20] Madhu GN, Harish S. Complementary feeding practice among mothers of children aged six months to two years admitted in a tertiary care hospital. IJCP; 5 (1). 2018: 97-100.

[21] Senarath, Upul \& Godakandage, Sanjeeva \& Jayawickrama, Hiranya \& Siriwardena, Indika. (2012). Determinants of inappropriate complementary feeding practices in young children in Sri Lanka: Secondary data analysis of Demographic and Health Survey 2006-2007. Maternal \& child nutrition. 8 Suppl 1. 60-77.
[22] Mihretie, Yimer. Maternal Knowledge on Complementary Feeding Practice and Nutritional Status of Children 6-23 Month in Jigjiga Town. Global Journal of Nutrition \& Food Science. 1. 2018.

[23] Promotion H, Fo P. Guiding Principles For Complementary Feeding Of The Breastfed Pan american Health Organization.

[24] Seram SN V, Punchihewa PMG. Knowledge on complementary feeding among parents of children aged 4-12 months attending a base hospital in a rural district in Sri Lanka. 2017; 46 (2): 139-47.

[25] Karigi LN, Mutuli LA. Socio-cultural perilakus and beliefs influencing infant and young child feeding in lubao sublocation Kakamega Country. 2016; 5 (1): 568-71.

[26] Berhanu Z, Alemu T, Argaw D. Predictors of inappropriate complementary feeding practice among children aged 6 to 23 months in Wonago District, South Ethiopia, 2017; case control study. 2019; 1-13.

[27] Gebremedhin S, Baye K, Bekele T, Tharaney M, Asrat Y, Sc $\mathrm{M}$, et al. Predictors of dietary diversity in children 6-23 months of age in largely food insecure area of South Wollo, Ethiopia. Nutrition. 2016. 